\title{
Interleukin-34 Gene Expression in the Peripheral Blood Leukocytes of Guillain-Barre Patients
}

\author{
Sina Rezaee, Mehrdokht Mazdeh², Mahdi Behzad ${ }^{3}$, Alireza Zamani ${ }^{4}$, Mohammad Mahdi \\ Eftekharian $^{3, *}$ \\ ${ }^{I}$ MSc in Immunology, Hamadan University of Medical Sciences, Hamadan, Iran \\ 2 Professor, Departement of Neurology, School of Medicine, Hamadan University of Medical Sciences, Hamadan, Iran \\ ${ }^{3}$ Associate Professor, Departement of Immunology, School of Medicine, Hamadan University of Medical Sciences, Hamadan, \\ Iran \\ 4 Professor, Departement of Immunology, School of Medicine, Hamadan University of Medical Sciences, Hamadan, Iran \\ * Corresponding Author: Mohammad Mahdi Eftekharian, Departement of Immunology, School of Medicine, Hamadan \\ University of Medical Sciences, Hamadan, Iran.Email: eftekharian@umsha.ac.ir
}

\begin{tabular}{|c|c|}
\hline & Abstract \\
\hline $\begin{array}{l}\text { Received: } 30.05 .2020 \\
\text { Accepted: } 11.08 .2020\end{array}$ & \multirow{3}{*}{$\begin{array}{l}\text { Background and Objective: Immune-mediated polyneuropathy is divided } \\
\text { into acute and chronic categories named as Guillain Barre syndrome (GBS) } \\
\text { and chronic inflammatory demyelinating polyradiculoneuropathy based on } \\
\text { the course of the disease. Although the basic mechanism of these conditions } \\
\text { has not been yet clarified, genes that regulate immune responses are putative } \\
\text { contributors in their development. The aim of this study was to compare the } \\
\text { blood expression level of } I L-34 \text { gene between patients with GBS and healthy } \\
\text { individuals. } \\
\text { Materials and Methods: In this case-control study, blood samples were } \\
\text { collected from } 53 \text { patients with GBS (i.e., } 33 \text { chronic patients and } 20 \text { acute } \\
\text { patients) and } 40 \text { healthy individuals. Gene expression levels in the studied } \\
\text { groups were measured using the real-time polymerase chain reaction } \\
\text { technique. Finally, statistical analysis was performed using SPSS software } \\
\text { (version } 16 \text { ) at a significance level of }<0.05 \text { was. } \\
\text { Results: The patient group consisted of } 36 \text { (67.93\%) males and } 17 \text { ( } 32.07 \% \text { ) } \\
\text { females. In addition, the healthy control group included } 27 \text { ( } 67.5 \% \text { ) males } \\
\text { and } 13 \text { (32.5\%) females. The results showed a significant increase in } I L-34 \\
\text { expression in the GBS patients, compared to that in the control group. } \\
\text { Conclusion: The findings of the present study revealed an increase in } I L-34 \\
\text { gene expression in patients with GBS. Accordingly, it seems that } I L-34 \text { gene } \\
\text { has an important role in the pathogenesis of this disease. } \\
\text { Keywords: Interleukin-34, Guillain-Barre Syndrome, Polyneuropathy }\end{array}$} \\
\hline $\begin{array}{l}\text { How to Cite this Article: } \\
\text { Rezaee S, Mazdeh M, Behzad } \\
\text { M, Zamani A, Eftekharian MM. } \\
\text { Interleukin-34 Gene Expression } \\
\text { in the Peripheral Blood } \\
\text { Leukocytes of Guillain-Barre } \\
\text { Patients. Avicenna J Clin Med. } \\
\begin{array}{l}2020 ; \quad 27(2): \quad 77-84 . \quad \text { DOI: } \\
\text { 10.29252/ajcm.27.2.77 }\end{array}\end{array}$ & \\
\hline & \\
\hline
\end{tabular}




\title{
بيان ثرن اينتر لوكين FF در سلول هاى خون محيطى افر اد مبتلابه سندرم تيلن باره
}

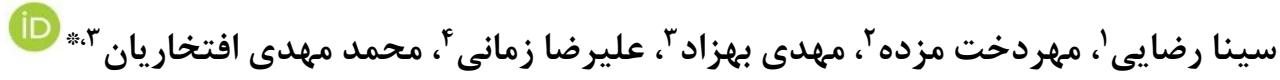

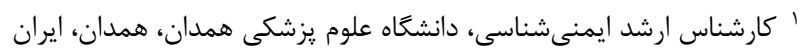

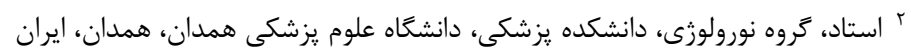

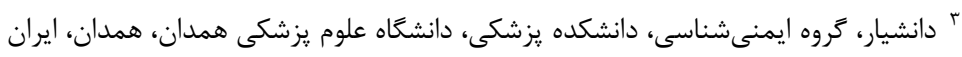

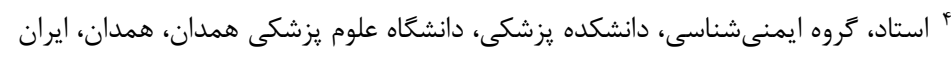
* نويسنده مسئول: محمد مهدى افتخاريان، كروه ايمنىشناسى، دانشكده يزشكى، دانشخاه علوم يزشكى همدان، همدان، ايران. ايميل: eftekharian@umsha.ac.ir

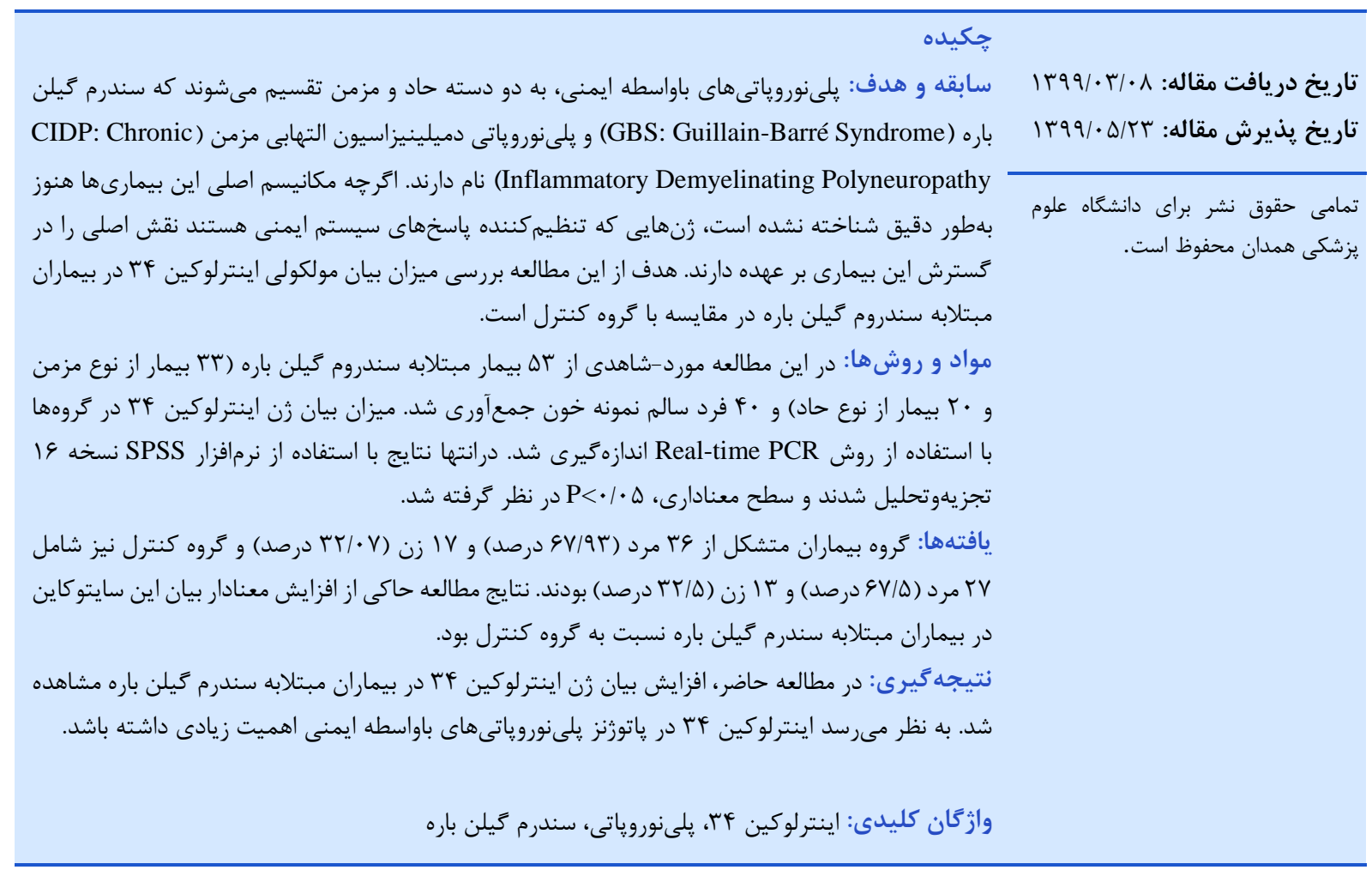

واكسنها تأكيد كردهاند. ابتلا به اين بيمارى با تروما و عمل إحل

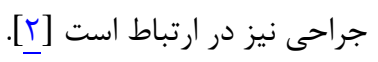

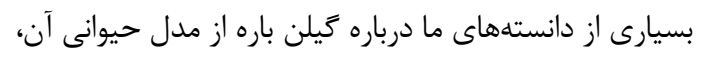

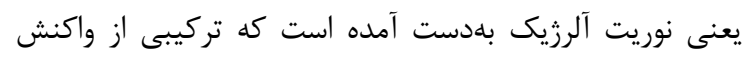

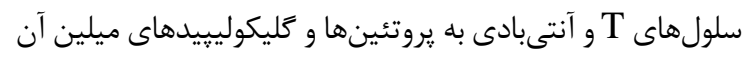

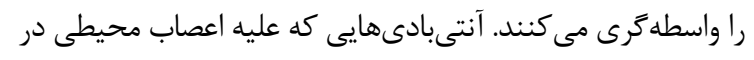

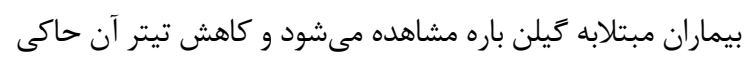

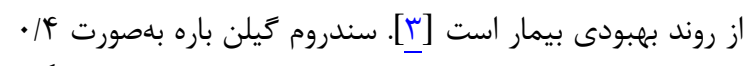

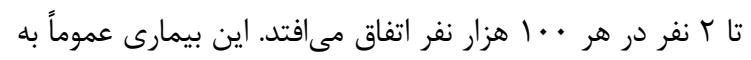

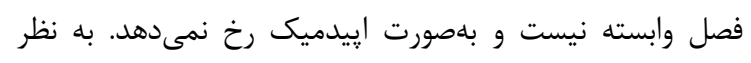

سندرم كيلن باره شامل كروهى از بيمارىهاى نوروياتيك

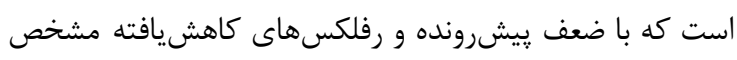

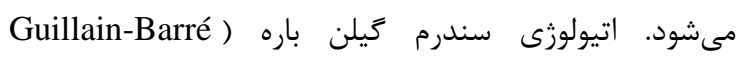

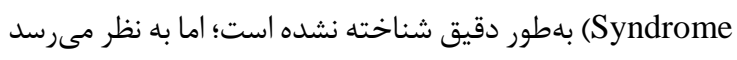

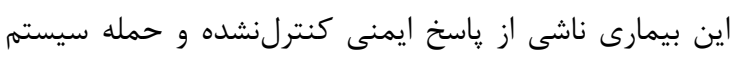

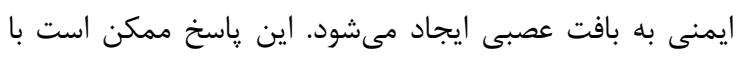

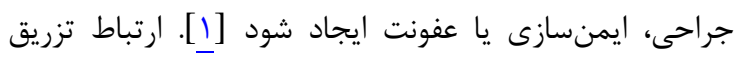

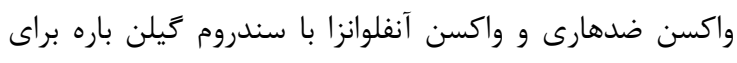

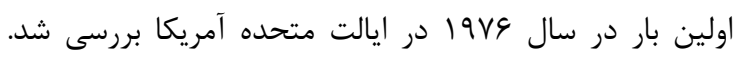

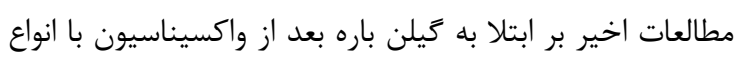


آنتىبادى عليه كانعليوزيد سبب فعالشدن بيشتر كميلمان نسبت به زمانى مىشود كه آنتىبادى عليه كانگليوزيد منفرد ساخته مىشود [1].

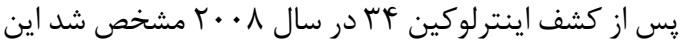

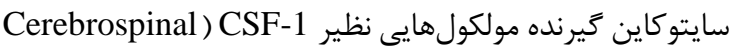
Receptor-type tyrosine-protein ) PTPRZ1 (Fluid [9] و و (CD138)syndecan-1) است. (phosphatase zeta اينترلوكين MF مىتواند نقشهاى متنوعى در محافظت سيستم

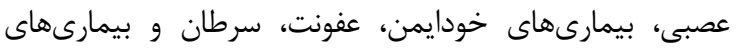

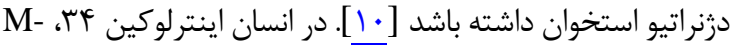
GM- و (macrophage colony-stimulating factor) CSF Granulocyte-macrophage colony-stimulating ) CSF (factor بقا و تمايز مونوسيتها به ماكروفازها را موجب مىشوند.

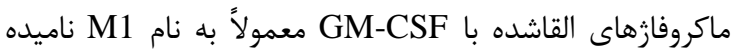

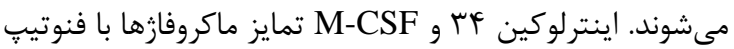

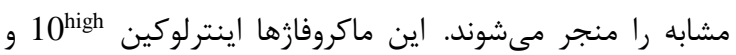

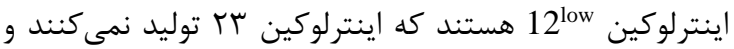

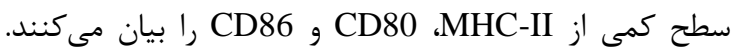
ماكروفازهاى القاشده با اينترلوكين F س و M-CSF ميزان كمترى

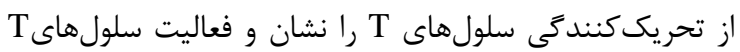

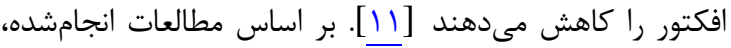

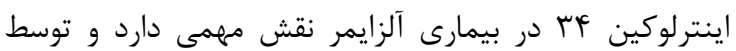
نورونها ترشح مىشود. همجنين سلولهاى ميكرو إنليال رسيتور

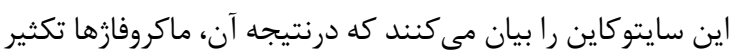

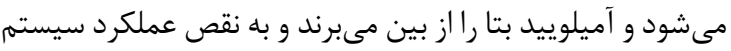

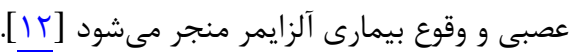
با توجه به موارد يادشده، اين مطالعه با هدف تعيين ميزان بيان

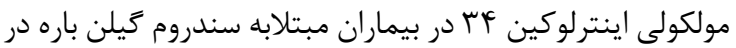

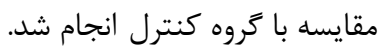

\section{مواد و روشها}

اين مطالعه مورد-شاهدى، روى دو گروه از افراد انجام شد كه

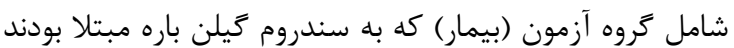

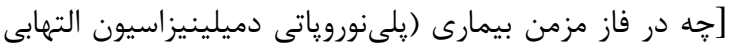

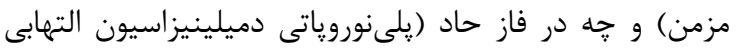
حاد )] و كروه كنترل (سالم) كه به اين بيمارى مبتلا نبودند.

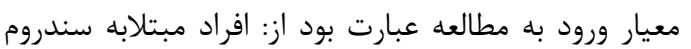

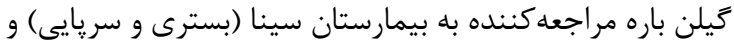
كلينيك تخصصى امام خمينى همدان كه وجود اين بيمارى در آنها قطعى شده است.

معيار خروج عبارت بود از: سابقه ابتلا به ساير بيمارىهاى زمينهاى و خودايمن.

معيار ورود براى گروه كنترل نيز شامل افراد سالمى بود كه

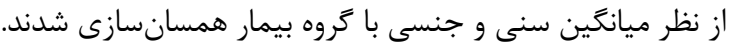

مىرسد شيوع اين بيمارى در مردان بيشتر از زنان باشد. اين

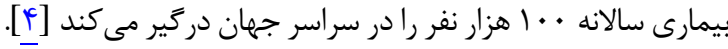

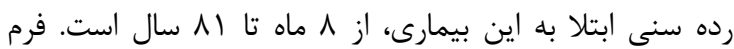

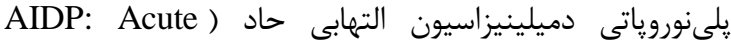
اين (Inflammatory Demyelinating Polyneuropathy بيمارى علت •9 درصد سندروم گيلن باره در ارويا و آمريكاى

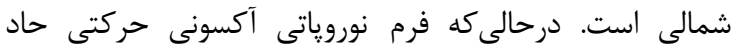
و نوروياتى (AMAN: Acute Motor Axonal Neuropathy) آكسونى حسى-حركتى حاد (AMSAN: Acute Motor-)

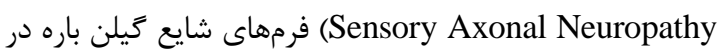
آسيا، آمريكاى جنوبى و مركزى هستند [ه]].

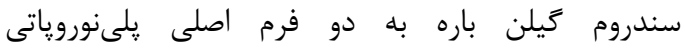

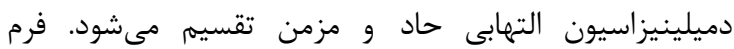

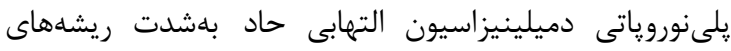

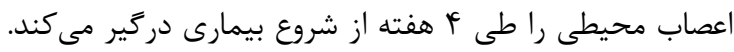

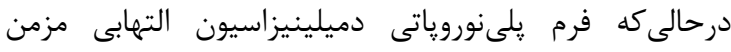

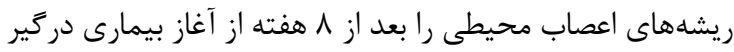

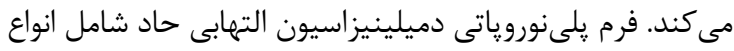
نوروياتى آكسونى حركتى حاد، نوروياتى آكسونى حسى -حرئى آنى

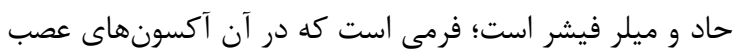
حسى و حركتى بهشدت تخريب مىشوند. فرم يلىنوروياتى

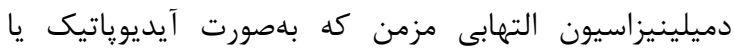

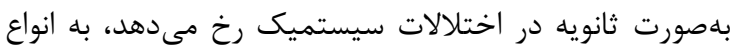
MADSAM: Multifocal Acquired Demyelinating ) DADS: Distal ) و (Sensory And Motor neuropathy (Aquired Demyelinating Sensory Neuropathy تقسيمبندى شده و در اصطلاح بهعنوان نوروياتى حركتى

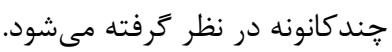
يلىنوروياتى دميلينيزاسيون التهابى حاد فرمى است درد كه

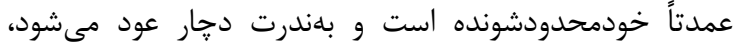

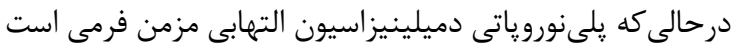
كه بلندرت تكفازى است و توانايى عود مجدد دارد [ع]. بر اساس مستندات موجود، نقش سيستم ايمنى در بروز

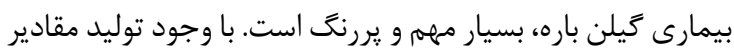

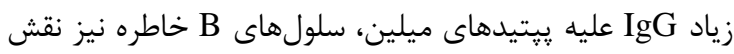

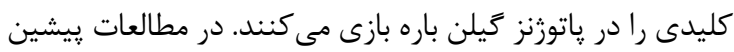

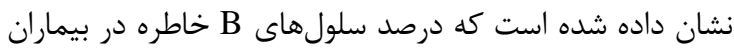

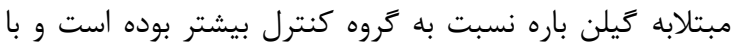

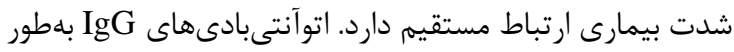

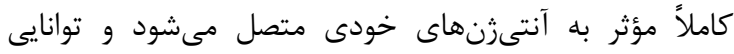

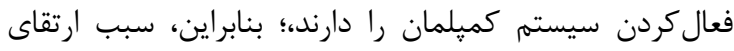

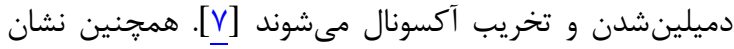

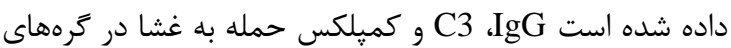

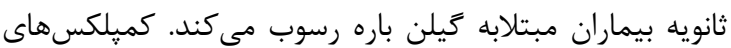


جدول ا: دما و زمانهاى دستخاه ترمال سايكلر براى سنتز أنDNA

\begin{tabular}{|c|c|}
\hline دما (سانتى گراد) & زمان (دقيقه) \\
\hline$r \Delta^{0}$ & $\Delta$ \\
\hline$\Delta \Delta^{0}$ & 4. \\
\hline$\wedge \Delta^{0}$ & $\Delta$ \\
\hline
\end{tabular}

ترمال سايكلر (Techne) ساخت آلمان استفاده شد. مشخصات

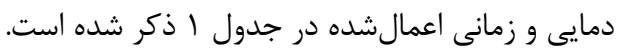

\section{طراحى يرايمر}

طراحى يرايمر براى زن اصلى و زن مرجع، با كمك نرمافزار نسخه Allele ID

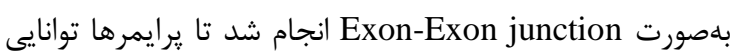

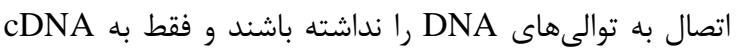
متصل شوند. درنتيجه وجود DNA درون نمونه

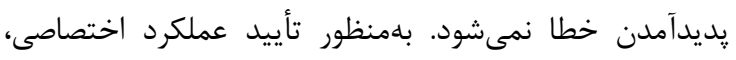

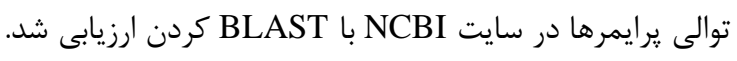
در جدول r مشخصات برايمرهاى استفادهده آمده است.

\section{Real-time PCR آزما يش}

در اين بخش از روش سايبرگرين و دستخاه ريل تايم شركت (Light cycler-96) Roche ساخت كشور آلمان استفاده شد.

$$
\text { در جدول ب مشخصات سيكلهاى اعمالشده آمده است. }
$$

حاصل از واكنش Real-Time PCR با تعداد نسخه

cDNA

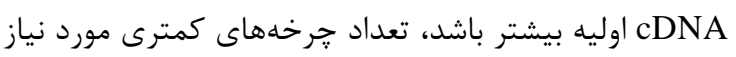

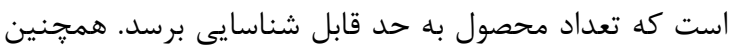

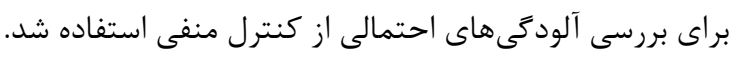

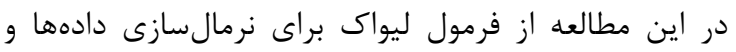

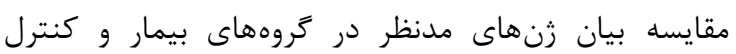

$$
\text { استفاده شد: }
$$

$\Delta \mathrm{Ct}($ test or control $)=\mathrm{Ct}($ target $)-\mathrm{Ct}$ (reference)

براى مقايسه ميزان بيان زنهاى مدنظر در گروه بيمار و
معيار خروج نيز ابتلا به سندرم گيلن باره و ساير بيمارىهاى

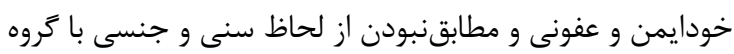
بيمار بود.

براى تعيين تعداد نمونه با توجه به اينكه مطالعه مشابهى بود

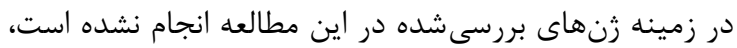

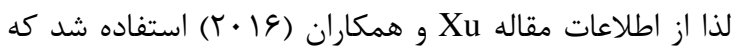

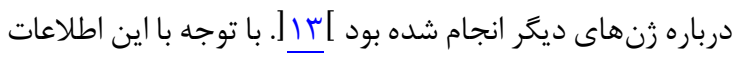

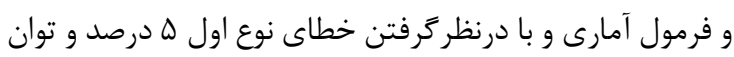

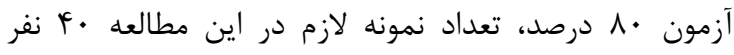

بهدست آمد.

\section{تعداد افراد مطالعهشده و نمونهكيرى از آنها}

از كاه بيمار مبتلابه سندروم كيلن باره در استان همدان

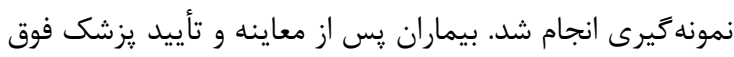

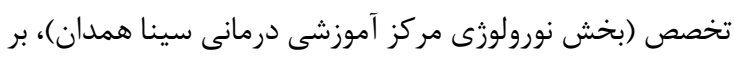

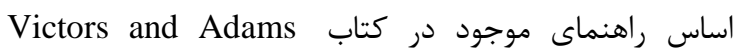
principles of neurology واجد شرايط بودن، ·ل ميلىليتر خون وريدى در لوله خلأ

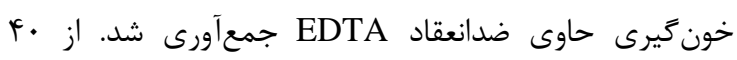
داوطلب گروه كنترل نيز خون خيرى انجام شد.

استخراج RNA/ز خون تام

بدين منظور از كيت استخراج RNA محصول شركت Gene مترج (Gene All Hybrid-RTM Blood RNA) ALL جنوبى استفاده شد. براى بررسى كميت RNA استخراجشده از

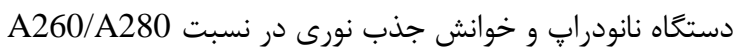

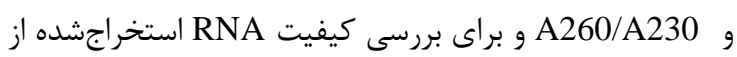

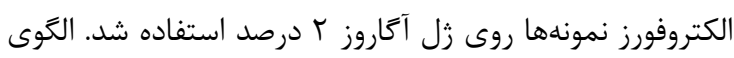

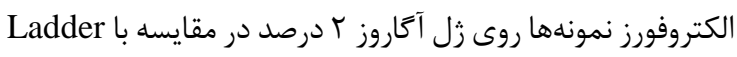
نشاندهنده كيفيت RNA استخراجشده است.

سنتز cDNA

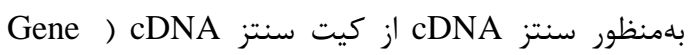
(ALL-HyperScript ${ }^{\mathrm{TM}}$

\begin{tabular}{|c|c|c|c|}
\hline اندازه محصول & طول برايمر & توالى يرايمر & ثن \\
\hline 1.1 & $\begin{array}{l}\text { rI } \\
\text { rt }\end{array}$ & $\begin{array}{l}\text { F: CTGTACTGCTCCTGCTGTAAC } \\
\text { R: CATACTGCAATGAGGGCTCTG }\end{array}$ & اينترلوكين Pr \\
\hline
\end{tabular}

جدول r: مشخصات يرايمرهاى استفادهده

\begin{tabular}{|c|c|c|c|}
\hline تعداد سيكلهها & زمان & دما (سانتى & مر حله \\
\hline 1 & • ( (دقيقه) & 90 & فعالسازى يليمراز \\
\hline f. & • 1 (ثانيه) & 90 & دناتوراسيون \\
\hline & ا (دقيقه) & q. & اتصال ير ايمر / اكستنشن \\
\hline
\end{tabular}

جدول ب: مراحل واكنش Real-Time PCR 


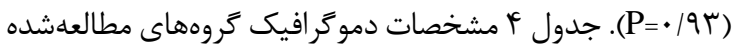
را نشان مى دهد.

بررسى ميزان بيان ثن /ينترلوكين F م در بين تروههاى مطالعهشده

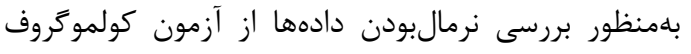

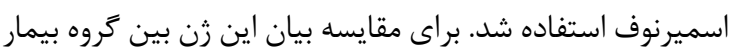

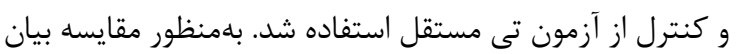

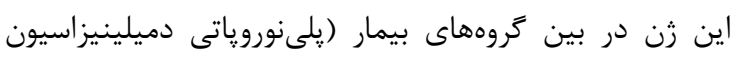

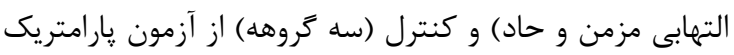

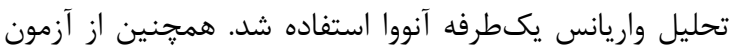
توكى براى مقايسه ميانگين دوبهدو كروهها استفاده شد. مقادير

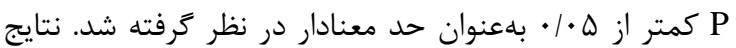

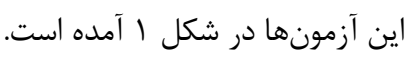

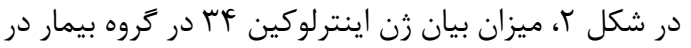

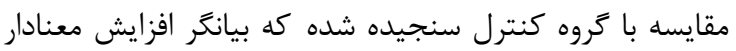

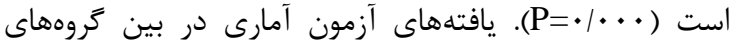

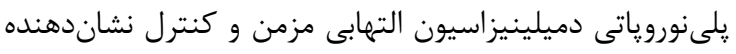

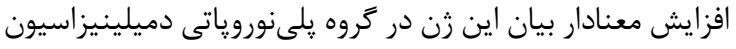

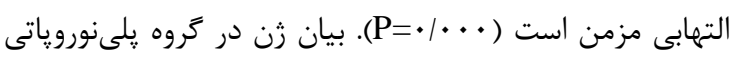

كنترل از محاسبه

بلهمنظور تحليل دادههاى Real-time PCR از نرمافزار نسخه 19 و آزمون هاى كولموكروف اسميرنف، تى مستقل آنساي

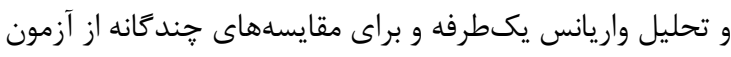

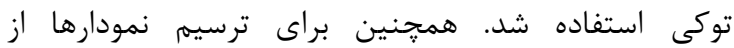
GraphPadPerism معنى داربودن در نظر كرفته شد.

\section{يافته ها}

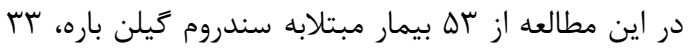

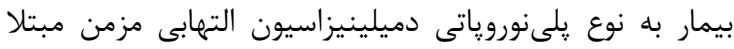

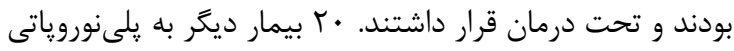

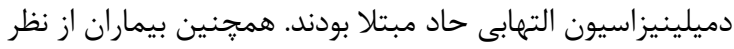

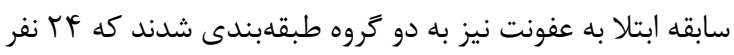

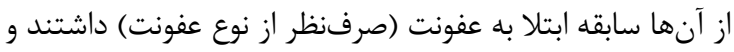

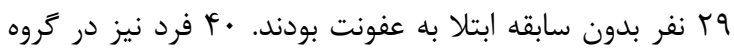

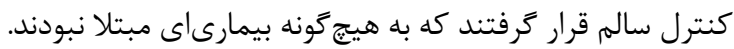

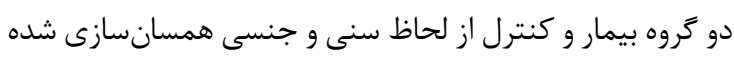

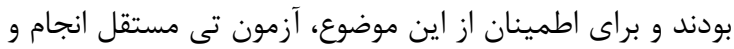

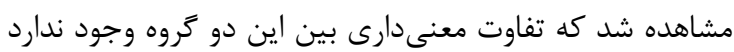

جدول f): مشخصات دموكرافيك، توزيع جنسيتى و توزيع سنى افراد مطالعهشده

\begin{tabular}{|c|c|c|c|c|}
\hline انحر افمعيار土 ميانغين & $\begin{array}{c}\text { تعداد (درصد) } \\
\text { تردان }\end{array}$ & $\begin{array}{c}\text { تعداد (درصد) } \\
\text { زنان }\end{array}$ & تعداد & تروه \\
\hline$\Delta \cdot / r \cdot \pm r / r$ & $(\varepsilon 9 / V) r$ & $(r \cdot / r)) \cdot$ & r & يلى نوروياتى دميلينيزاسيون التهابى مزمن \\
\hline$\Delta r / 9 \Delta \pm r / \wedge q$ & $(v \cdot))^{f}$ & $(r \cdot)^{q}$ & $r \cdot$ & يلى نوروياتى دميلينيزاسيون التهابى حاد \\
\hline$\uparrow \wedge / \vee q \pm r / \varphi ६$ & $(99 \mid 9) 19$ & $(r M / \mathcal{F}) \mathcal{G}$ & rF & بيماران با سابقه ابتلا به عفونت \\
\hline r & $(9 \Delta / \Delta) 19$ & $(r F / Q)) \cdot$ & rq & بيماران بدون سابقه ابتلا به عفونت \\
\hline$\Delta I / G r \pm r / \Delta F$ & $(\Phi V / Q) Y V$ & $(Y T / D) \mid r$ & $r$. & كروه كنترل \\
\hline
\end{tabular}
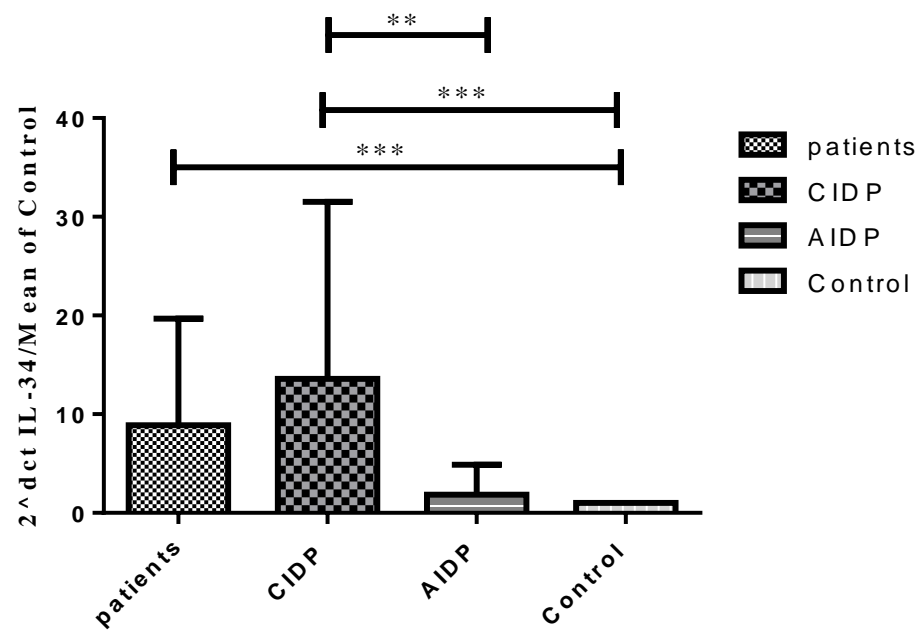

G roups

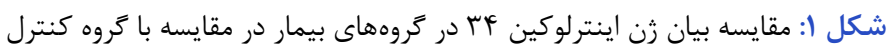

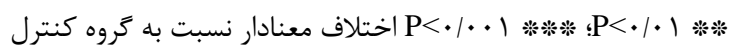




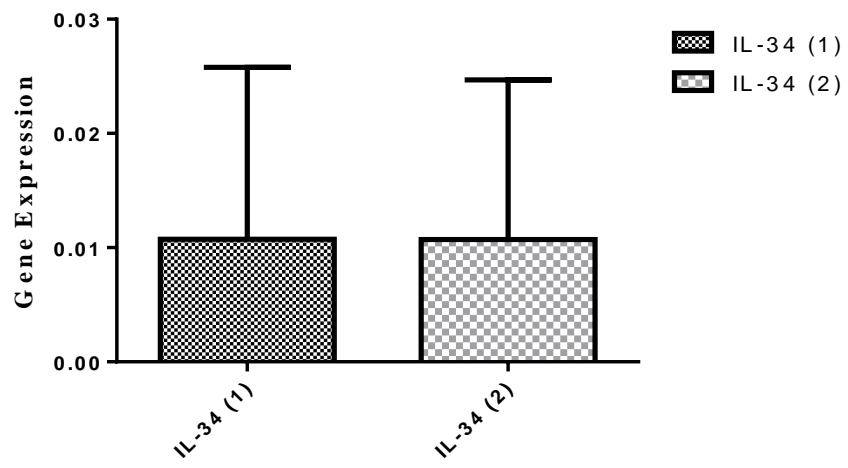

GroupS

شكل Y: مقايسه سابقه ابتلا به عفونت و ميزان بيان زن اينترلوكين ب ب در گروه بيمار

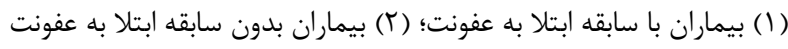

آيويتوز ها و درنتيجه تخريب CSF-1R ب

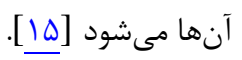

اينترلوكين MF سـ سـايتوكاينى است كه از نظر عملكرد مشابه

(Macrophage Colony Stimulating Factor) M-CSF اسـت. در مطالعه Bostrom و همكارانش در سـال سا • ب نشان

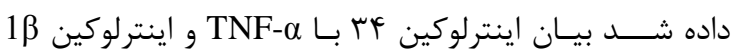

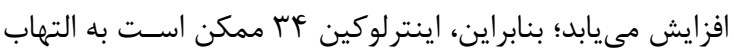

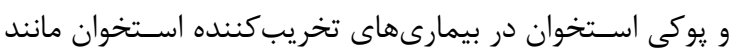

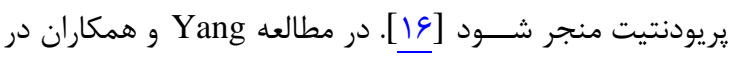

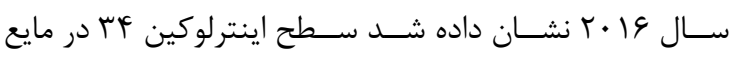

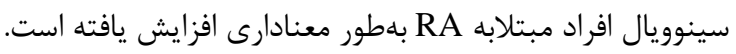

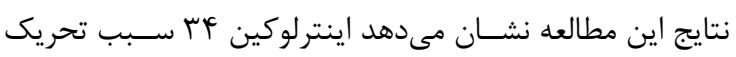

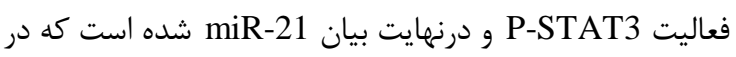

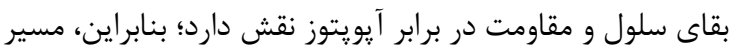

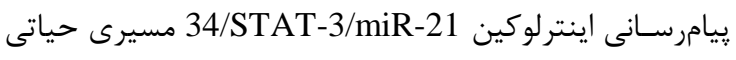

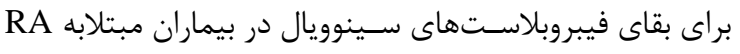
اسـت كه از اين مسـير مىتوان بلعنوان اهداف درمانى استفاده

كرد [IV] نتايج مطالعه Tian و همكارانش در سال Y I إ. نشان داد

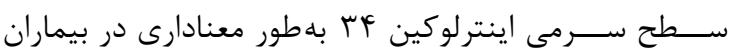

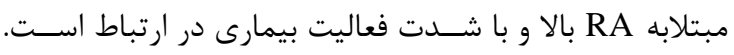

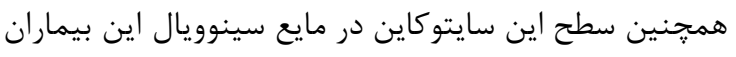

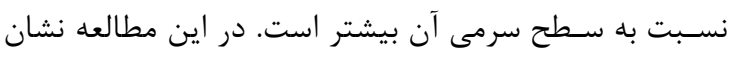

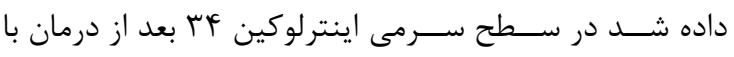

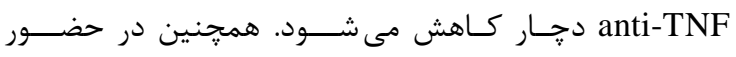

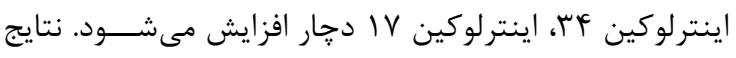

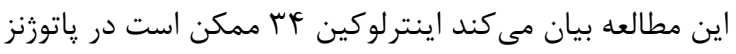
RA

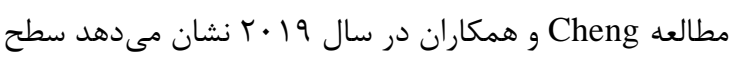

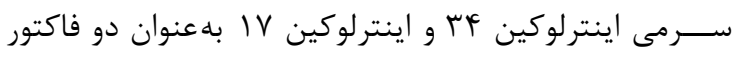
التهابى در بيماران نفريت لويوسى (LN: Lupus nephritis)
دميلينيزاسيون التهابى مزمن نسبت به گروه حاد افزايش معنادار

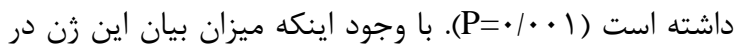

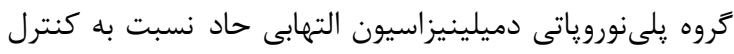
افزايش داشته، اما اين اختلاف معنادار نبوده است (ب (P= (P).

\section{مقايسه ميزان بيان ثن /ينترلوكين F سابقه /بتلا به عفونت و بلدون سابقه /بتلا} در اين مطالعه بهمنظور بررسى نرمالبودن دادهها از آزمون

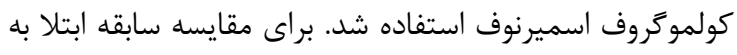

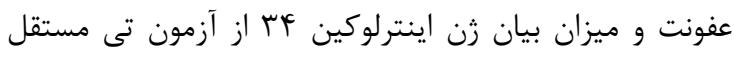

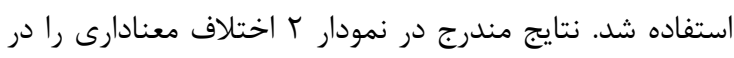

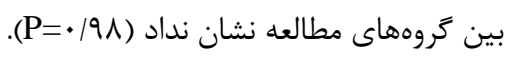

در مطالعه حاضر سطح بيان زن اينترلوكين عاب در سه گروه

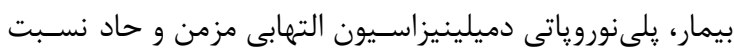

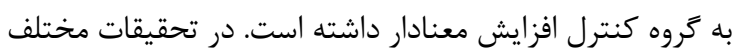

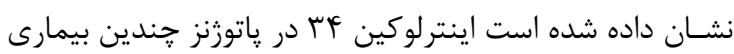

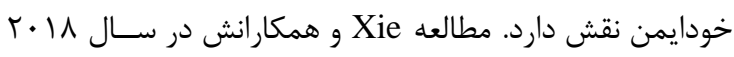

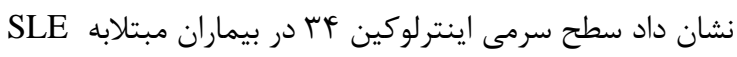

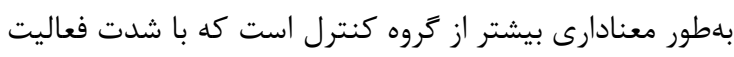

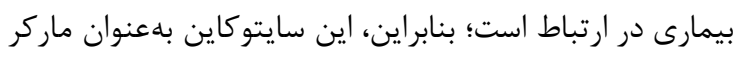

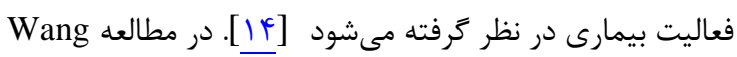

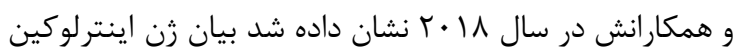
HT: ) و MF (Hashimoto's thyroiditis

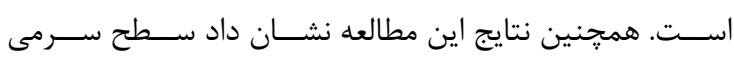

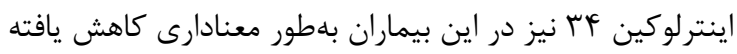

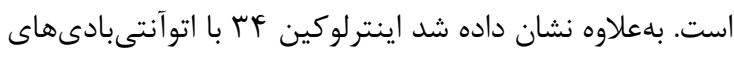

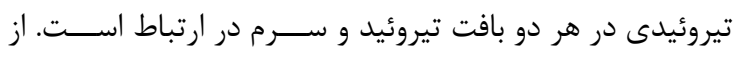

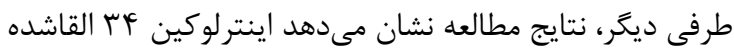


همسو با مطالب ذكرشده، نتايج مطالعه Liu و همكارانش در

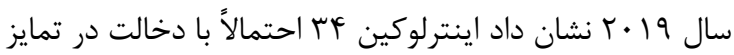

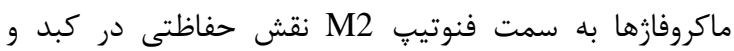

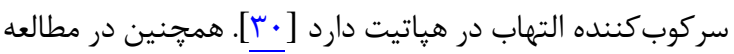

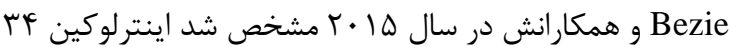

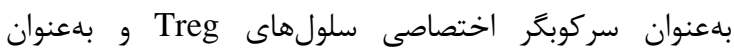

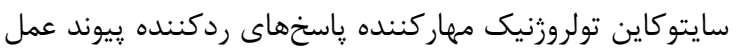

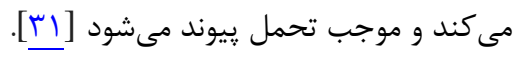

\section{نتيجه تيرى}

در اين مطالعه افزايش بيان اينترلوكين بF بر در بيماران

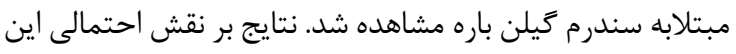

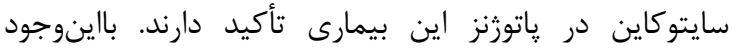

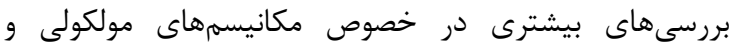
فرايندهاى ايمونوياتوزنز اين سايتوكاين در جامعله آمارى بزركتر لازم به نظر مىرسد.

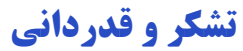

اين مقاله از يايان نامه دوره كارشناسى ارشد ايمنىشناسى

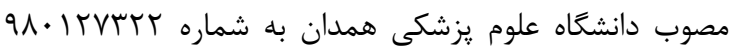

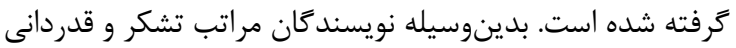

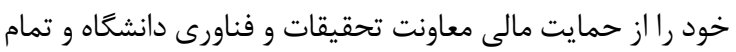
عزيزانى اعلام مىدارند كه در تكميل اين يروزه همكارى داشتند.

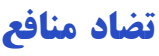

در اين مطالعه هيجَّونه تضاد منافعى كزارش نشده است.

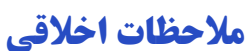

يُووهشَّران در تمامى مراحل انجام اين مطالعه به مفاد بيانيه

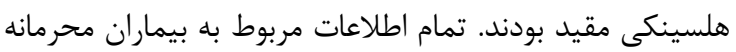

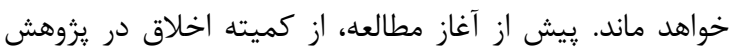

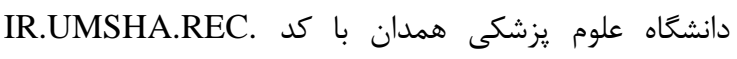

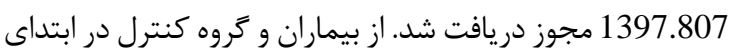

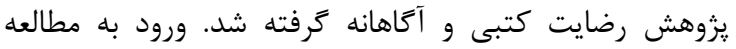

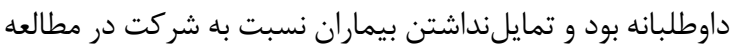

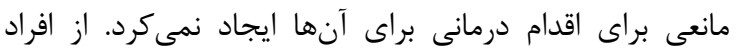

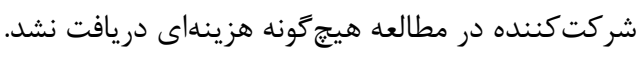

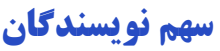

نويسنده اول (يُوهشكر اصلى) تهيه يرويوزال، انجام امور

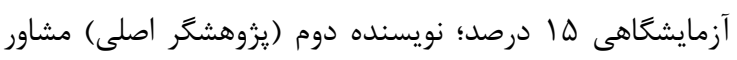

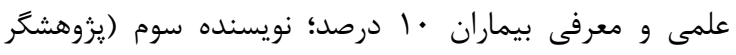

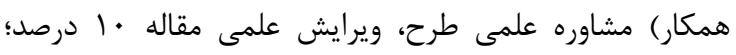

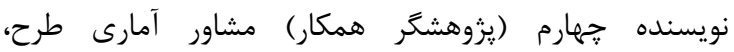

بـهـور معنادارى افزايش يافته اســت كه بهعنوان ماركرهاى

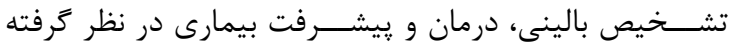

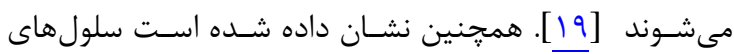

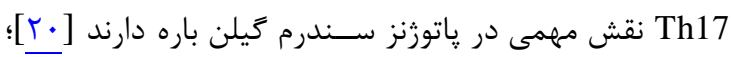

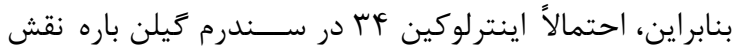

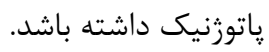

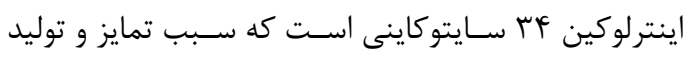

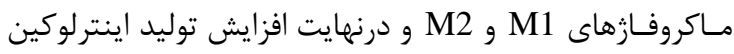

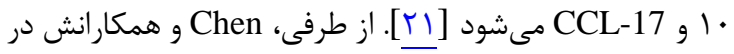

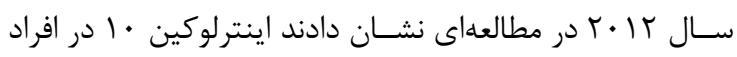

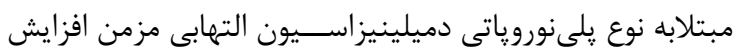

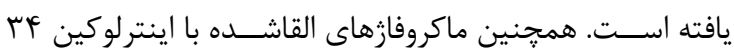

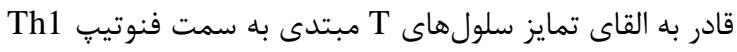

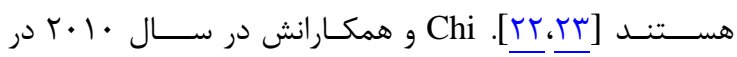

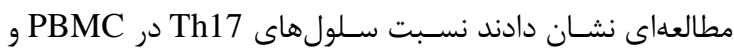

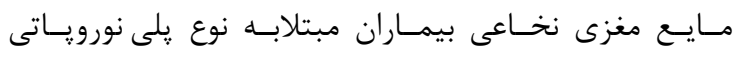

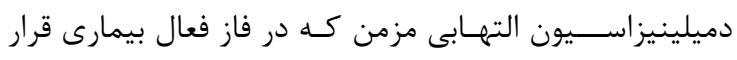

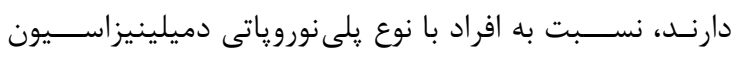

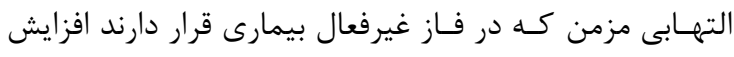

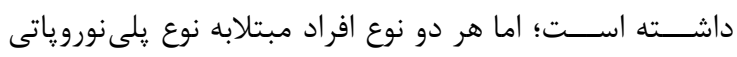

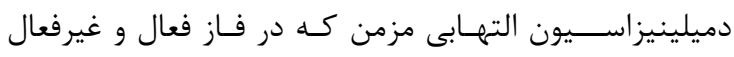

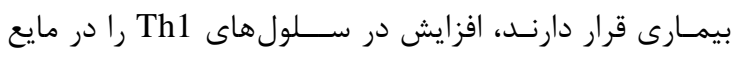

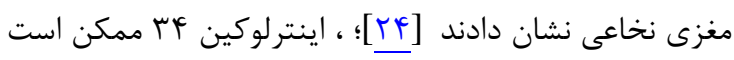

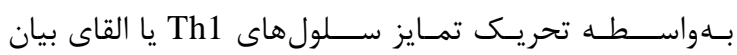

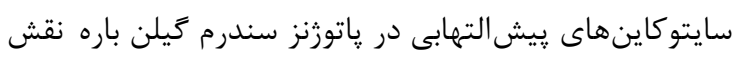

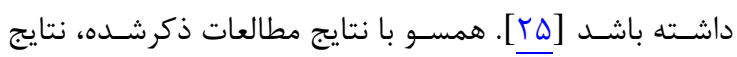

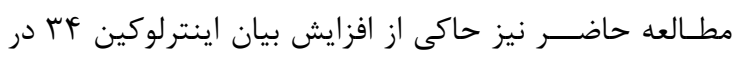

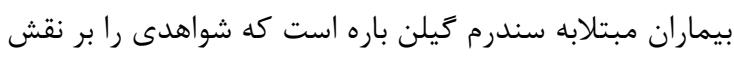

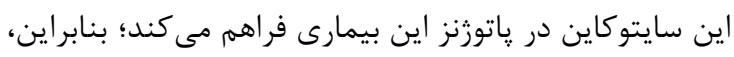

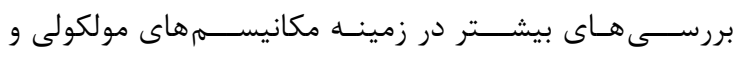

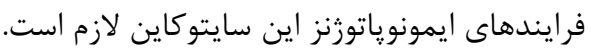

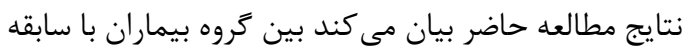

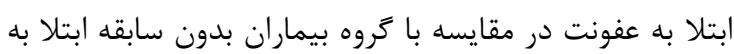

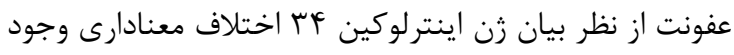

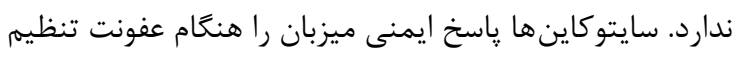

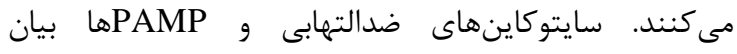

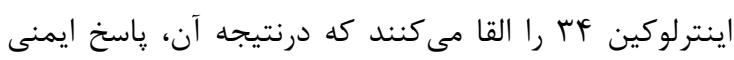

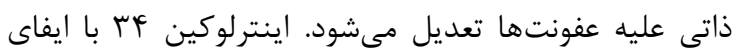

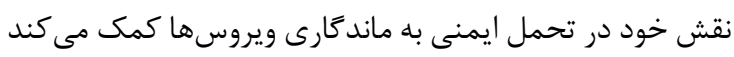

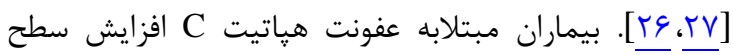

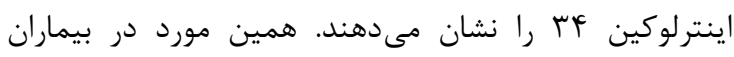

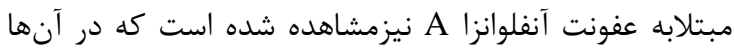

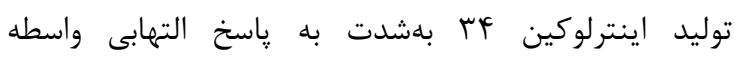

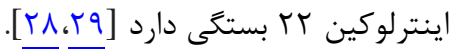




$$
\text { حمايت مالى }
$$

\section{REFERENCES}

1. Walling $\mathrm{AD}$, Dickson G. Guillain-Barre syndrome. Am Fam Physician. 2013;87(3):191-7. PMID: 23418763

2. Willison HJ, Jacobs BC, van Doorn PA. Guillain-Barre syndrome. Lancet. 2016;388(10045):717-27. PMID: 26948435 DOI: 10.1016/S0140-6736(16)00339-1

3. Dimachkie MM, Barohn RJ. Guillain-Barré syndrome and variants. Neurol Clin. 2013;31(2):491-510. PMID: 23642721 DOI: 10.1016/j.ncl.2013.01.005

4. Lambracht-Washington D, Wolfe GI. Cytokines in Guillain-Barré syndrome: a lesson in time. Arch Neurol. 2011;68(4):427-8. PMID: 21482922 DOI: 10.1001/archneurol.2011.47

5. Zhang HL, Zheng XY, Zhu J. Th1/Th2/Th17/Treg cytokines in Guillain-Barré syndrome and experimental autoimmune neuritis. Cytokine Growth Factor Rev. 2013;24(5):443-53. PMID: 23791985 DOI: 10.1016/j.cytogfr.2013.05.005

6. Mathey EK, Park SB, Hughes RA, Pollard JD, Armati PJ, Barnett $\mathrm{MH}$, et al. Chronic inflammatory demyelinating polyradiculoneuropathy: from pathology to phenotype. J Neurol Neurosurg Psychiatry. 2015;86(9):973-85. PMID: 25677463 DOI: 10.1136/jnnp-2014-309697

7. Yuki N. Ganglioside mimicry and peripheral nerve disease. Muscle Nerve. 2007;35(6):691-711. PMID: 17373701 DOI: 10.1002/mus.20762

8. Rodriguez Y, Rojas M, Pacheco Y, Acosta-Ampudia Y, RamirezSantana C, Monsalve DM, et al. Guillain-Barre syndrome, transverse myelitis and infectious diseases. Cell Mol Immunol. 2018;15(6):547-62. PMID: 29375121 DOI: 10.1038/cmi.2017.142

9. Segaliny AI, Brion R, Mortier E, Maillasson M, Cherel M, Jacques Y, et al. Syndecan-1 regulates the biological activities of interleukin-34. Biochim Biophys Acta. 2015;1853(5):1010-21. PMID: 25662098 DOI: 10.1016/j.bbamcr.2015.01.023

10. Guillonneau C, Bezie S, Anegon I. Immunoregulatory properties of the cytokine IL-34. Cell Mol Life Sci. 2017;74(14):2569-86. PMID: 28258292 DOI: 10.1007/s00018-017-2482-4

11. Foucher ED, Blanchard S, Preisser L, Descamps P, Ifrah N, Delneste Y, et al. IL-34- and M-CSF-induced macrophages switch memory T cells into Th17 cells via membrane IL-1alpha. Eur $J$ Immunol. 2015;45(4):1092-102. PMID: 25545357 DOI: $10.1002 /$ ji. 201444606

12. Segaliny AI, Mohamadi A, Dizier B, Lokajczyk A, Brion R, Lanel $\mathrm{R}$, et al. Interleukin-34 promotes tumor progression and metastatic process in osteosarcoma through induction of angiogenesis and macrophage recruitment. Int $J$ Cancer. 2015;137(1):73-85. PMID: 25471534 DOI: 10.1002/ijc.29376

13. Xu J, Gao $C$, Zhang F, Ma X, Peng X, Zhang $R$, et al. Differentially expressed lncRNAs and mRNAs identified by microarray analysis in GBS patients vs healthy controls. Sci Rep. 2016;6:21819. PMID: 26898505 DOI: 10.1038/srep21819

14. Xie HH, Shen H, Zhang L, Cui MY, Xia LP, Lu J. Elevated serum interleukin-34 level in patients with systemic lupus erythematosus is associated with disease activity. Sci Rep. 2018;8(1):3462. PMID: 29472590 DOI: 10.1038/s41598-018-21859-Z

15. Wang S, Liu Y, Zhao N, Cui X, Huang M, Li Y, et al. IL-34 expression is reduced in hashimoto's thyroiditis and associated with thyrocyte apoptosis. Front Endocrinol. 2018;9:629. PMID: 30405534 DOI: 10.3389/fendo.2018.00629

16. Boström EA, Lundberg P. The newly discovered cytokine IL-34 is expressed in gingival fibroblasts, shows enhanced expression by pro-inflammatory cytokines, and stimulates osteoclast differentiation. PloS One. 2013;8(12):e81665. PMID: 24339952 DOI: 10.1371/journal.pone.0081665

17. Yang S, Jiang S, Wang Y, Tu S, Wang Z, Chen Z. Interleukin 34 upregulation contributes to the increment of MicroRNA 21

$$
\begin{aligned}
& \text { روششناسى • ا درصد؛ نويسنده ينجم (يثزوهشگر اصلى) مسئول } \\
& \text { مكاتبات، طراحى يروزه، تدوين بخشهاى مختلف طرح، نگارش } \\
& \text { و ويرايش مقاله فه درصد. }
\end{aligned}
$$

expression through STAT3 activation associated with disease activity in rheumatoid arthritis. $J$ Rheumatol. 2016;43(7):1312-9. PMID: 27084907 DOI: $10.3899 /$ jrheum.151253

18. Tian Y, Shen H, Xia L, Lu J. Elevated serum and synovial fluid levels of interleukin-34 in rheumatoid arthritis: possible association with disease progression via interleukin-17 production. J Interferon Cytokine Res. 2013;33(7):398-401. PMID: 23421370 DOI: 10.1089/jir.2012.0122

19. Cheng Y, Yang X, Zhang X, An Z. Analysis of expression levels of IL-17 and IL-34 and influencing factors for prognosis in patients with lupus nephritis. Exp Ther Med. 2019;17(3):2279-83. PMID: 30783486 DOI: 10.3892/etm.2019.7168

20. Debnath M, Nagappa M, Subbanna M, Sundaravadivel P, Talukdar PM, Shivakumar V, et al. Th17 pathway signatures in a large Indian cohort of Guillain Barré syndrome. J Neuroimmunol. 2018;323:125-30. PMID: 30196825 DOI: 10.1016/j.jneuroim. 2018.08.001

21. Boulakirba S, Pfeifer A, Mhaidly R, Obba S, Goulard M, Schmitt T, et al. IL-34 and CSF-1 display an equivalent macrophage differentiation ability but a different polarization potential. Sci Rep. 2018;8(1):256. PMID: 29321503 DOI: 10.1038/s41598-01718433-4

22. Chen H, Ende N, Souayah N. The cytokine profile of chronic inflammatory demyelinating polyneuropathy (P06.134). Neurology. 2012;78(1 Suppl):P06.134.

23. Lindau R, Mehta RB, Lash GE, Papapavlou G, Boij R, Berg G, et al. Interleukin-34 is present at the fetal-maternal interface and induces immunoregulatory macrophages of a decidual phenotype in vitro. Hum Reprod. 2018;33(4):588-99. PMID: 29579271 DOI: 10.1093/humrep/dey037

24. Chi LJ, Xu WH, Zhang ZW, Huang HT, Zhang LM, Zhou J. Distribution of Th17 cells and Th1 cells in peripheral blood and cerebrospinal fluid in chronic inflammatory demyelinating polyradiculoneuropathy. J Peripher Nerv Syst. 2010;15(4):34556. PMID: 21199106 DOI: 10.1111/j.1529-8027.2010.00294.x

25. Sivieri S, Ferrarini AM, Lolli F, Matà S, Pinto F, Tavolato B, et al. Cytokine pattern in the cerebrospinal fluid from patients with GBS and CIDP. J Neurol Sci. 1997;147(1):93-5. PMID: 9094066 DOI: 10.1016/s0022-510x(96)00319-x

26. Baghdadi M, Endo H, Tanaka Y, Wada H, Seino KI. Interleukin 34, from pathogenesis to clinical applications. Cytokine. 2017; 99:139-47. PMID: 28886491 DOI: 10.1016/j.cyto.2017.08.020

27. Zelante T, Ricciardi-Castagnoli $P$. The yin-yang nature of CSF1R-binding cytokines. Nat Immunol. 2012;13(8):717-9. PMID: 22814343 DOI: 10.1038/ni.2375

28. Ge Y, Huang M, Yao YM. Immunomodulation of interleukin-34 and its potential significance as a disease biomarker and therapeutic target. Int J Biol Sci. 2019;15(9):1835-45. PMID: 31523186 DOI: $10.7150 /$ ijbs.35070

29. Preisser L, Miot C, Le Guillou-Guillemette H, Beaumont E, Foucher ED, Garo E, et al. IL-34 and macrophage colonystimulating factor are overexpressed in hepatitis $\mathrm{C}$ virus fibrosis and induce profibrotic macrophages that promote collagen synthesis by hepatic stellate cells. Hepatology. 2014;60(6):187990. PMID: 25066464 DOI: 10.1002/hep.27328

30. Liu Y, Liu H, Zhu J, Bian Z. Interleukin-34 drives macrophage polarization to the M2 phenotype in autoimmune hepatitis. Pathol Res Pract. 2019;215(8):152493. PMID: 31201067 DOI: 10.1016/j.prp.2019.152493

31. Bézie S, Picarda E, Ossart J, Tesson L, Usal C, Renaudin K, et al. IL-34 is a Treg-specific cytokine and mediates transplant tolerance. J Clin Invest. 2015;125(10):3952-64. PMID: 26389674 DOI: $10.1172 /$ JCI81227 